\title{
Developing understanding beyond the given knowledge and new methodologies for analyses in CSCL
}

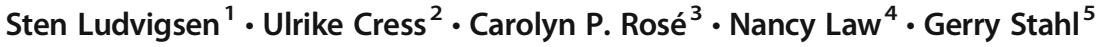 \\ Published online: 21 November 2018 \\ (C) International Society of the Learning Sciences, Inc. 2018
}

\section{Introduction}

In schools and educational settings, students increasingly need to learn content and perspectives that are not given as part of the curriculum. When working with digital resources embedded in digital environments and infrastructures, students' and teachers' tasks often become more complex and need more social and cognitive framing. The sequential organization of textbooks has historically provided teachers and students with well-established structures for student actions. However, when other resources become more important, designers, teachers, and students need to establish additional forms of supports and scaffolds for learning. The first two papers in this issue address this theme, focusing on how to support students in their work with digital resources.

The other two papers look at important methodological issues in computer-supported collaborative learning to analyze and describe collaborative work. The third paper problematizes the coding-and-counting approach in CSCL and provides an alternative method

Sten Ludvigsen

s.r.ludvigsen@iped.uio.no

Ulrike Cress

u.cress@iwm-tuebingen.de

Carolyn P. Rosé

cprose@cs.cmu.edu

Nancy Law

nlaw@hku.hk

Gerry Stahl

Gerry@ijCSCL.org

Faculty of Educational Sciences, University of Oslo, Oslo, Norway

2 Leibniz-Institut für Wissensmedien (Knowledge Media Research Center), Tübingen, Germany

3 Carnegie Mellon University Language Technologies Institute and HCI Institute, Pittsburgh, PA, USA

4 University of Hong Kong, Hong Kong, China

5 Drexel University, Philadelphia, PA, USA 
for analyzing and understanding temporality in learning. The authors of this paper argue that epistemic network analysis offers a better account of how learning emerges over time than coding-and- counting. The fourth paper argues for the importance of a well-formulated theoretical framework in CSCL research, and demonstrates that different approaches to big data methods can shed light on learning and knowledge development in CSCL when framed using sociocognitive conflicts and productive friction as the main concepts.

\section{Organizing productive learning: Design and the importance of dynamic teacher support}

The first paper by Line Ingulfsen, Anniken Furberg, and Torunn A. Strømme, "Students' Engagement with Real-Time Graphs in CSCL settings", emphasizes the relationship between the design of learning settings, content-specific artefacts, and student-teacher interaction. Although concepts and principles such as design of environments, orchestration, and scripts have been at the core of numerous CSCL studies, studies that analyze student-teacher interactions (e.g. Arnseth and Krange 2016; Schwarz et al. 2018) are surprisingly few.

Design-based research has been one of the major positions within CSCL. It usually involves the design of the microstructures of a classroom or other educational setting, with a focus on design principles, the development and use of computational artifacts, and roles and expectations for teachers and students. An influential strand of contributions in CSCL demonstrated that in knowledge-building classes, the expectations for students and teachers are rather different than in traditional classrooms with teacher dominance (for a recent contribution, see Fu et al. 2016). We know from many design-based research studies that changing the culture of participation is both a short- and long-term task. The design of the setting and the computational artifacts can enhance cognitive and cultural processes in learning settings and schools (Overdijk et al. 2012; Law et al. 2017).

The study by Ingulfsen et al. follows the tradition of design-based CSCL research, looking at the design of CSCL with a specific focus on how students use real-time labs in natural settings. Real-time labs consist of software and devices for measurement, and they produce graphic visualizations of science experiments. Ingulfsen et al. report on an experiment related to ocean acidification. By performing a detailed interaction analysis, the authors show how students and teachers worked together to develop their conceptual sensemaking. The analysis delves into those encounters in which students struggled with understanding the graphs. Some students needed support to focus on the relevant features of the graphs and to understand the experimental results in relation to underlying scientific principles; they also needed both procedural and conceptual support. To provide this support, the teacher used both eliciting and elaboration strategies and gave the students prompts to help them interpret the graphs. In this setting, the teacher also provided students with contextual guidance, providing a relevance structure in which they could work. Ingulfsen et al. used the notion of the zone of proximal development (Vygotsky 1986) to show how the students needed to utilize a medley of scaffolds to make sense of the computational artifacts. Such coordination work is demanding, requiring both the students and the teacher to activate advanced social and cognitive functions. The teacher serves as an adaptive expert whose input closed cognitive, social, and design gaps in order to support the students' understanding of real-time labs. 


\section{Visualization of socio-scientific problems: Identifying valid knowledge}

In the paper by Anne Solli, Thomas Hilman, and Åsa Mäkitalö, titled "Rendering Controversial SocioScientific Issues Legible Through Digital Mapping Tools", the authors investigate how students in upper secondary school develop understanding of complex information in online environments. This study can be seen as an exploratory investigation in a natural setting. In many countries, schools increasingly use digital environments for student learning. When the textbook is not the only resource used in the classroom, students need scaffolds beyond those given in the sequential organization of the textbook. Connecting multiple sources of information is a more complex process than following structured content laid out in a textbook. Studies of students' information processing and learning with multiple texts and of representations in sciences and other knowledge areas have grown in prominence as a significant area of study in educational psychology (e.g., Strømsø and Kammerer 2017) and in digital literacy (e.g., Fitzgerald and Palincsar 2017).

In the study by Solli et al., the students worked with a software called Gephi, which allowed them to represent content in a visual form. Gephi uses statistical techniques and algorithms to construct graphs based on specified sets of nodes and links. It is most commonly used for social network analysis. The software has a number of features that students can use to advance their interpretation of data and the phenomena that they investigate. Gephi allowed the students to explore, manipulate, and visualize online data as sets of nodes and connected through edges. They learn how representations of the chosen content could be re-presented in order to create meaning for collaborative efforts.

The students in the study by Solli et al. were given a scientific controversy to investigate. The authors describe the use of Gephi in six activities intended to structure and scaffold student action and collaboration. Their analysis of the data is based on interaction analysis (e.g. Furberg 2016) with focus on the process through which language produces knowledge in the interaction. The collaboration is seen as a progression of steps toward understanding how the software works and what it represents. The network mapping tool supported the students when they critically selected, analyzed, and reviewed the data that they found online. The collaborative meaning-making processes made it possible for the students to produce new knowledge that extended their previous understanding of the controversy. Another interesting finding of the study is that students had to work out new categories for themselves. Working with emergent categories can be seen as advanced conceptual work that involves framing and reformulation of tasks.

The controversy that the students were investigating did not necessarily have a correct answer. In the classroom, both an exploratory position (which was not part of the curriculum) and a more curriculum-oriented interpretation were given. The study's authors emphasize that further investigation is needed to determine how advanced tasks can be scaffolded when scientific controversies are used to advance students' digital literacy as a design principle that can lead to in-depth learning.

\section{New methods in CSCL: Temporality and learning}

In the paper by Andras Csanadi, Brendan Egan, Ingo Kollar, David Williamsson Shaffer, and Frank Fischer, "When coding-and-counting is not enough: Using Epistemic Network Analysis (ENA) to Analyze Verbal Data in CSCL Research", the authors address one of the most 
important issues in learning research - how to understand temporality. In many different areas of learning research, temporality has been seen as a basic problem that must be addressed in a more advanced way (e.g., Furberg 2016; Ludvigsen et al. 2011; Reimann 2009). Different positions here refer to cognitive, sociocognitive, and sociocultural perspectives on temporality. In the now classical paper by Brown (1992) in the Journal of the Learning Sciences, she argued that we can't understand learning if we do not analyze how it unfolds over time. Indeed, a classical psychological experiment (which might take around one hour) has little to contribute to the understanding of learning new concepts in, for example science, which takes weeks, months, or even years (e.g. Furberg et al. 2013; White 2018). In CSCL and other fields, the arguments for and against coding - and, even more importantly, what kind of coding should be considered relevant - are very important. Understanding collaborative learning with computational artifacts necessitates the study of a specific phenomenon. The critique of codes has often been that they lead to fragmentation of data and the phenomenon, while the critique of interactional analysis and related approaches has been that they only show examples and do not support statistical generalization.

The paper by Csandi et al. advances the methodological repertoire in the analysis of data in CSCL. The authors argue that the tradition of exclusively using a coding and counting strategy in analysis neglects the temporal nature of verbal data, and fails to account for the fact that actions and activities are played out in sequences over time. The authors test coding and counting analysis and compare it with epistemic network analysis. This analytic technique is based on discourse analysis, which models temporal occurrences of codes in discourse. The authors analyzed the same dataset using both epistemic network analysis, and coding and counting analysis, and these analyses are then compared. The authors' research questions are as follows: (1) Which technique provide the best explanation of group differences with respect to learners' engagement in different learning actions? (2) To what extent are the results of the first research question due to systematic temporal co-occurrences between learning actions? The authors show that epistemic network analysis provides a better account of the temporal patterns between the sociocognitive events than coding and counting. This paper demonstrates that new methods of data analysis in CSCL can offer new and important insights in the field.

\section{Big data in mass collaboration online environments}

In the final paper "Using Big Data Techniques for measuring productive frication in Mass collaboration online environments", Peter Holtz, Joachim Kimmerle, and Ulrike Cress describe and discuss three prototypical big data methods that can be used to analyze CSCL on the individual and social group/collective level. Cress and colleagues have worked on the conceptualization of collaboration in large groups for more than 10 years. They put forward the cognitive-systemic stance, which builds on cognitive psychology, to investigate conceptual change from a general system theory view. Their argument is that we need to connect both individual cognitive systems and the individual's interactions with the larger environmentthe social systems. They further argue that social systems in themselves develop features, capacities, and complexities (Cress and Kimmerle 2008; Cress et al. 2018; Jeong et al. 2017).

The authors hypothesize that knowledge development at the levels of both individual and social system is triggered by productive friction, which implies that the resolution of sociocognitive conflicts are part of actions and activities. The questions about methodologies 
that the authors raise concern different ways of using big data to analyze and explain how individuals and systems learn. Holtz et al. present three approaches to big data, using Wikipedia environments as their empirical example: automatic text classification, knowledge dynamics in Wikipedia articles cluster analysis, and social network analysis. Their analysis shows that all three approaches can provide insights into the ways that learning and knowledge development take place. The authors emphasize a very important stance in CSCL: analysis of big data must be framed by a clear and well-developed theoretical framework. Holtz et al. use sociocognitive conflicts and productive friction as the main concepts within their broader framework.

\section{The squib: Do CSCL settings and environments change teaching and learning?}

We follow up with a squib that addresses a provocation from the paper by Wise and Schwarz (2017). Hod et al. give a very substantial response to the provocation about the impact of CSCL on educational change. Such changes can be conceptualized in microstructures in classrooms (1) and schools (2) and on a large scale in school systems (3) - at three levels. Hod et al. argue that the provocation is based on too limited a view of the kind of impacts that have already been achieved in the CSCL community and can be achieved in the future. They emphasize that some major CSCL initiatives have actually produced sustainable change at the three mentioned levels, and the design-centric research practice partnership model will continue to do so in the coming years. They argue that the community needs focus especially on the relationship between microstructures and the connection between the classrooms in schools.

From an editorial perspective, the debate and argument that follow Wise and Schwarz's paper contribute to a very productive discussion within the CSCL community. We welcome new and provocative squibs to further enhance the field.

Publisher's Note Springer Nature remains neutral with regard to jurisdictional claims in published maps and institutional affiliations.

\section{References}

Arnseth, H. C., \& Krange, I. (2016). What happens when you push the button?: Analyzing the functional dynamics of concept development in computer-supported science inquiry. International Journal of Computer-Supported Collaborative Learning, 11(4), 479-502.

Brown, A. L. (1992). Design experiments: Theoretical and methodological challenges in creating complex interventions in classroom settings. Journal of the Learning Sciences, 2(2), 141-178.

Cress, U., \& Kimmerle, J. (2008). A systemic and cognitive view on collaborative knowledge building with wikis. International Journal of Computer-Supported Collaborative Learning, 3(2), 105-122.

Cress, U., Stahl, G., Rose, C., Law, N., \& Ludvigsen, S. (2018). Forming social systems by coupling minds at different levels of cognition: Design, tools, and research methods. International Journal of ComputerSupported Collaborative Learning, 13(3), 235-240.

Fitzgerald, M. S., \& Palincsar, A. S. (2017). Peer-mediated Reading and writing in a digital, multimodal environment. Reading and Writing Quarterly, 33(4), 309-326.

Fu, E. L. F., van Aalst, J., \& Chan, C. K. K. (2016). Toward a classification of discourse patterns in asynchronous online discussions. International Journal of Computer-Supported Collaborative Learning, 11(4), 441-478.

Furberg, A. (2016). Teacher support in computer-supported lab work: Bridging the gap between lab experiments and students' conceptual understanding. International Journal of Computer-Supported Collaborative Learning, 11, 89-113. 
Furberg, A., Kluge, A., \& Ludvigsen, S. (2013). Student sensemaking with diagrams in a computer- based setting. International Journal of Computer-Supported Collaborative Learning, 8(1), 41-64.

Jeong, H., Cress, U., Moskaliuk, J., \& Kimmerle, J. (2017). Joint interactions in large online knowledge communities: The A3C framework. International Journal of Computer-Supported Collaborative Learning, 12, 113-151.

Law, N., Liang, L., \& Cheng, K. (2017). A self-organizing network of schools that transform teacher and student learning through socio-technical co-evolution. In B. Smith, M. Borge, E. Mercier, \& K. Y. Lim (Eds.), Proceedings of the 12th international conference on computer supported collaborative learning (Vol. 1, pp. 431-438). Philadelphia: ISLS.

Ludvigsen, S., Rasmussen, I., Krange, I., Moen, A., \& Middleton, D. (2011). Intersecting trajectories of participation: Temporality and learning. In S. Ludvigsen, A. Lund, I. Rasmussen, \& R. Säljö (Eds.), Learning across sites: New tools, infrastructures and practices (pp. 105-121). Cambridge: Cambridge University Press.

Overdijk, M., Van Diggelen, W., Kirschner, P. A., \& Baker, M. (2012). Connecting agents and artifacts in CSCL: Towards a rationale of mutual shaping. International Journal of Computer-Supported Collaborative Learning, 7(2), 193-210.

Reimann, P. (2009). Time is precious: Variable- and event-centred approaches to process analysis in CSCL research. International Journal of Computer-Supported Collaborative Learning, 4(3), 239-257.

Schwarz, B. B., Prusak, N., Swidan, O., Livny, A., Gal, K., \& Segal, A. (2018). Orchestrating the emergence of conceptual learning: A case study in a geometry class. International Journal of Computer-Supported Collaborative Learning, 13(2), 189-211.

Strømsø, H. I., \& Kammerer, Y. (2017). Epistemic cognition and reading for understanding in the Internet age. In J. A. Greene, W. A. Sandoval, \& I. Bråten (Eds.), Handbook of epistemic cognition (pp. 230-246). New York, NY/London, England: Routledge.

Vygotsky, L. (1986). Thought and language. Cambridge: MIT Press.

White, T. (2018). Connecting levels of activity with classroom network technology. International Journal of Computer-Supported Collaborative Learning, 13(1), 93-122.

Wise, A. F., \& Schwarz, B. B. (2017). Visions of CSCL: Eight provocations for the future of the field. International Journal of Computer-Supported Collaborative Learning, 12(4), 423-467. 